\title{
Genotype-Guided Hydralazine Therapy
}

\author{
Kimberly S. Collins ${ }^{a}$ Anthony L.J. Raviele ${ }^{a}$ Amanda L. Elchynski ${ }^{b}$ \\ Alexander M. Woodcock ${ }^{a}$ Yang Zhao ${ }^{b}$ Rhonda M. Cooper-DeHoff ${ }^{b}$ \\ Michael T. Eadon ${ }^{a}$ \\ aDepartment of Medicine, Indiana University School of Medicine, Indianapolis, IN, USA; \\ ${ }^{b}$ Department of Pharmacotherapy and Translational Research, University of Florida, Gainesville, FL, USA
}

\section{Keywords}

Hydralazine $\cdot \mathrm{N}$-acetyltransferase $2 \cdot$ Pharmacogenetics .

Resistant hypertension

\begin{abstract}
Background: Despite its approval in 1953, hydralazine hydrochloride continues to be used in the management of resistant hypertension, a condition frequently managed by nephrologists and other clinicians. Hydralazine hydrochloride undergoes metabolism by the $\mathrm{N}$-acetyltransferase 2 (NAT2) enzyme. NAT2 is highly polymorphic as approximately $50 \%$ of the general population are slow acetylators. In this review, we first evaluate the link between NAT2 genotype and phenotype. We then assess the evidence available for genotypeguided therapy of hydralazine, specifically addressing associations of NAT2 acetylator status with hydralazine pharmacokinetics, antihypertensive efficacy, and toxicity. Summary: There is a critical need to use hydralazine in some patients with resistant hypertension. Available evidence supports a significant link between genotype and NAT2 enzyme activity as 29 studies were identified with an overall concordance between genotype and phenotype of $92 \%$. The literature also supports an association between acetylator status and hydralazine concentration, as fourteen of fifteen identified
\end{abstract}

studies revealed significant relationships with a consistent direction of effect. Although fewer studies are available to directly link acetylator status with hydralazine antihypertensive efficacy, the evidence from this smaller set of studies is significant in 7 of 9 studies identified. Finally, 5 studies were identified which support the association of acetylator status with hydralazine-induced lupus. Clinicians should maintain vigilance when prescribing maximum doses of hydralazine. Key Messages: NAT2 slow acetylator status predicts increased hydralazine levels, which may lead to increased efficacy and adverse effects. Caution should be exercised in slow acetylators with total daily hydralazine doses of $200 \mathrm{mg}$ or more. Fast acetylators are at risk for inefficacy at lower doses of hydralazine. With appropriate guidance on the usage of NAT2 genotype, clinicians can adopt a personalized approach to hydralazine dosing and prescription, enabling more efficient and safe treatment of resistant hypertension.

(c) 2020 S. Karger AG, Basel

\section{Introduction}

The application of pharmacogenetics to antihypertensive dose and agent selection is still a nascent endeavor. No current society guidelines from the clinical pharma- karger@karger.com

www.karger.com/ajn

Karger ${ }^{\prime}=$
(C) 2020 S. Karger AG, Basel

950 W. Walnut St. E20

Indianapolis, IN 46202 (USA)

meadon@iupui.edu 
cogenetics implementation consortium (CPIC) exist for any antihypertensive agent. Nephrologists and other providers frequently evaluate and treat resistant hypertension, individualizing a regimen from the best combination of 3 or more antihypertensive agents [1], often from trial and error. Nephrologists and other providers managing resistant hypertension would benefit from a mechanism to expeditiously arrive at an optimal antihypertensive regimen.

The hydralazine hydrochloride and $\mathrm{N}$-acetyltransferase 2 (NAT2) drug-enzyme pair is an attractive candidate that can be used to implement genotype-guided therapy. NAT2 is a very important pharmacogene, contributing to phase 2 hepatic metabolism of many drugs [2]. As of 2020, the National Center for Biotechnology Information (NCBI) lists 10 laboratories that provide commercial testing for NAT2 genotype on its genetic testing registry, raising the question of what guidance is provided by these commercial laboratories to clinicians [3]. The US Food \& Drug Administration (FDA) labels for Apresoline (hydralazine hydrochloride) monotherapy and the combination therapy BiDil (isosorbide dinitrate and hydralazine hydrochloride) both support the use of acetylation status to determine bioavailability $[4,5]$. The hydralazine drug label states, "slow acetylators generally have higher plasma levels of hydralazine and require lower doses to maintain control of blood pressure." However, no suggestions on specific dose adjustments are provided. In February 2020, the FDA released an updated table of pharmacogenetic associations, in which NAT2 enzyme activity was included as a predictor of hydralazine systemic concentration [6].

Hydralazine is an old drug, having received FDA approval in 1953. However, it is still commonly used in resistant hypertension and as a first-line therapy for afterload reduction in African Americans with heart failure [7]. In the Indiana University Healthcare system, NAT2 genotyping has been performed clinically as part of an antihypertensive pharmacogenetics panel since 2017, with results available to the clinician in the electronic health record $[8,9]$. Among the 580 individuals who received antihypertensive pharmacogenetic testing in a kidney clinic, $13 \%$ of all renal patients were prescribed hydralazine (alone or in combination with isosorbide dinitrate), including 25\% of all African Americans. Approximately $50 \%$ of these individuals are fast or intermediate acetylators (i.e., normal or intermediate metabolizers). Fast or intermediate acetylators require 140-225\% of the dose that slow acetylators (i.e., poor metabolizers) require to have the same hydralazine exposure [10]. Given the wide range of FDA-approved total oral daily dos-

Genotype-Guided Hydralazine Therapy es from $40 \mathrm{mg}$ daily to $300 \mathrm{mg}$, there is potential utility in dose adjustment and titration based on acetylation status. Slow acetylators are predicted to have higher circulating concentrations of the parent drug, with not only increased antihypertensive efficacy but also a higher potential risk of adverse events.

In this review, we examine the evidence surrounding genotype-guided dosing of hydralazine, briefly reviewing metabolism before establishing a critical link between NAT2 genotype and the NAT2 enzyme activity phenotype. Some of the evidence presented originates from an era before the completion of human genome sequencing. As a result, enzyme activity often serves as a surrogate for genotype. We then examine evidence linking enzyme activity or its predictive genotype to hydralazine drug levels, efficacy in blood pressure reduction, and adverse events, with a focus on drug-induced lupus.

\section{Hydralazine Metabolism}

Hydralazine hydrochloride is a parent drug and active compound which undergoes first-pass hepatic metabolism by the polymorphic NAT2 enzyme into primarily inactive metabolites (Fig. 1) [11]. The two acetylation pathways involve direct acetylation to form MTP and 3-OH-MTP, and oxidation to form an intermediate called 1-hydrazinophthalazine (HPZ), followed by acetylation to form $\mathrm{N}$-acetyl-hydrazine-phthalazinone $[2,12]$. The major circulating metabolite is $\mathrm{HPH}$, which may be renally excreted or undergo further metabolism. Older studies may also use the term acid-labile hydralazine, which refers to the sum of the concentration of parent hydralazine and its acid-labile metabolites like $\mathrm{HPH}$, which were indistinguishable on gas-liquid chromatography.

\section{Concordance between NAT2 Phenotype and Genotype}

The N-acetyltransferase (NAT2) acetylator phenotype is determined by measuring the pharmacokinetics of a NAT2 probe drug. This process entails orally administering the probe drug and measuring the parent and/or metabolite concentrations in the urine. A histogram of the parent/metabolite ratios or percentage of parent drug acetylated often yields a bimodal distribution through which the fast or slow metabolizer status can be differentiated. In some cases, a distinct intermediate group can be 
Fig. 1. Hydralazine metabolism pathway. Hydralazine undergoes acetylation by NAT2 via 2 pathways. Direct acetylation by NAT2 and cyclization to form MTP followed by oxidation to form $3 \mathrm{OH}-\mathrm{MTP}$, or oxidation to form HPZ followed by acetylation to form NAc-HPZ. HPH is the major metabolite found in circulation. Additional hydralazine metabolites not mentioned include phthalazinone, phthalazine, and 9-hydroxy-3-methyltriazolophthalazine. MTP, 3-methyl-1,2,4-triazolo-[3,4a] phthalazine; 3OH-MTP, 3-hydroxymethyl-1,2,4-triazolo-[3,4a] phthalazine; NAcHPZ, N-acetyl-hydrazine-phthalazinone; $\mathrm{HPH}$, hydralazine pyruvic acid hydrazone; HPZ, 1-hydrazinophthalazine.

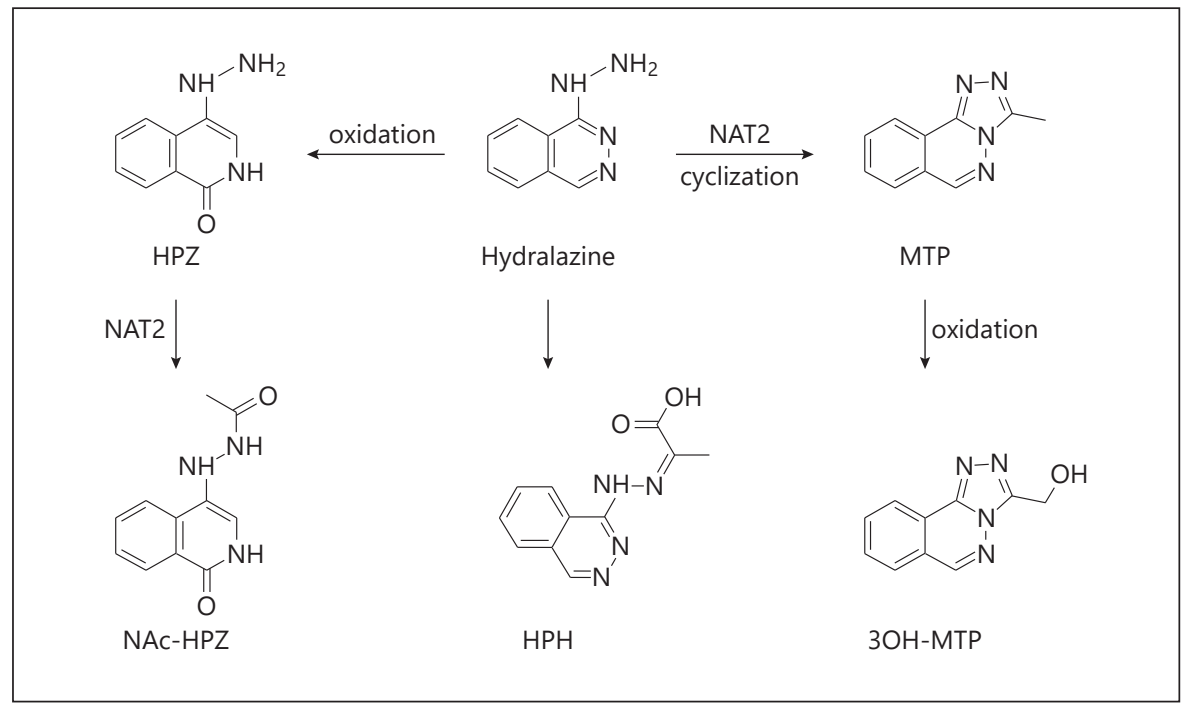

Table 1. NAT2 allele frequency and predicted function

\begin{tabular}{|c|c|c|c|c|c|c|c|}
\hline NAT2*allele & Variant & rs\# & Global MAF & African & Asian & European & Predicted function \\
\hline$* 4$ & None & None & & & & & Standard/wild type \\
\hline *5 & $341 \mathrm{~T}>\mathrm{C}$ & rs 1801280 & 0.43 & 0.67 & 0.03 & 0.55 & Reduced \\
\hline *6 & $590 \mathrm{G}>\mathrm{A}$ & rs1799930 & 0.29 & 0.25 & 0.25 & 0.29 & Reduced \\
\hline$* 7$ & $857 \mathrm{G}>\mathrm{A}$ & rs1799931 & 0.03 & 0.03 & 0.16 & 0.025 & Reduced \\
\hline${ }^{*} 11$ & $481 \mathrm{C}>\mathrm{T}$ & rs1799929 & 0.42 & 0.27 & 0.03 & 0.43 & Standard $^{\mathrm{a}}$ \\
\hline *12 & $803 \mathrm{~A}>\mathrm{G}$ & rs 1208 & 0.42 & 0.42 & 0.06 & 0.43 & Standard ${ }^{\mathrm{b}}$ \\
\hline *13 & $282 \mathrm{C}>\mathrm{T}$ & rs 1041983 & 0.33 & 0.43 & 0.43 & 0.32 & Standard $^{\mathrm{a}}$ \\
\hline *14 & $191 \mathrm{G}>\mathrm{A}$ & rs1801279 & 0.004 & 0.08 & 0 & 0.0004 & Reduced \\
\hline
\end{tabular}

MAF, minor allele frequency; NAT2, N-acetyltransferase 2. ${ }^{a}$ rs1799929 and rs1041983 are synonymous mutations without an amino acid substitution and are considered standard functioning alleles. ${ }^{\mathrm{b}}$ rs 1208 is a missense mutation conferring an amino acid substitution of lysine $(\mathrm{K})$ to arginine $(\mathrm{R})$. It is presently considered a standard functioning allele.

identified $[13,14]$. However, intermediate acetylators are frequently indistinguishable from fast acetylators and are considered functionally similar [15]. Although sulfamethazine is the gold standard for NAT2 phenotyping, other commonly used drugs to assess acetylator status include isoniazid or caffeine. In a study of 26 surgical patients, there was a significant positive correlation between caffeine and sulfamethazine phenotyping $(r=0.98)$. This acetylator activity also correlated with immunodetectable levels of NAT1 and NAT2 proteins $(r=0.92)$ [16].

By studying the family history of individuals classified as slow or fast acetylators, NAT2 acetylator status was discovered to be genetically inherited [17-19]. With the onset of sequencing and genotyping as available tools, sci- entists have identified the polymorphisms responsible for altered acetylation, and the polymorphisms have been directly correlated to the probe-drug phenotyping results. Across 29 different studies identified, a diverse array of populations was examined, including Asian Indian, African American, Canadian, Caucasian, Chinese, Emirati, Ethiopian, French, German, Greenlandic, Hawaiian, Hispanic, Hmong, Japanese, Latin American, Native South African, Pakistani, Polish, Russian, Swedish, and Swiss populations [13, 14, 20-47].

The genotypes most commonly assessed in $90 \%$ of these studies include the $* 5, * 6$, and ${ }^{*} 7$ alleles, all of which are associated with reduced function (Table 1 ). The $* 14$ reduced-functioning allele was only assessed in 9 studies 
but is predominantly found in individuals of African ancestry. In a study of 35 African Americans and 7 Caucasians, concordance was $90 \%$ when using caffeine phenotyping to align with the $* 4,{ }^{*} 5,{ }^{*} 6$, and ${ }^{*} 7$ alleles. However, the ${ }^{*} 14$ variant was identified in all 4 discordant individuals and was only present in African Americans. When reassessed with this variant allele, concordance was $100 \%$ [23]. The $5, * 6, * 7$, and ${ }^{*} 14$ alleles are all nonsynonymous variants. The synonymous $* 11$ normal functioning allele was assessed in 2 studies, and the ${ }^{*} 12$ (nonsynonymous) and $* 13$ (synonymous) normal functioning alleles were assessed in less than half of the studies. The overall concordance of NAT2 genotype to NAT2 enzymatic activity phenotype is very strong at $92 \%(4,060 / 4,398$ individuals $)$ across all 29 studies (Table 2).

There is evidence to suggest slow acetylators can be further subcategorized into slow and very slow acetylator phenotypes. Individuals with two copies of either the *6 or *7 allele have more profoundly reduced acetylation than those with the $* 5$ reduced-functioning allele $[26,40$, 48]. However, most studies measuring hydralazine concentration or blood pressure phenotypes do not separately analyze the $* 5$ allele from the $* 6$ or $* 7$ allele; thus, further evidence is required to understand whether a distinction in slow and very slow acetylators will prove clinically relevant. The * 12 and $* 13$ allelic functions may require a reassessment as well, since they have been associated with a discordance in phenotyping results [25]. For example, the ${ }^{*} 12$ allele is a missense variant despite its consideration as functionally normal, and the ${ }^{*} 13$ allele has been associated with decreased acetylation capacity compared to the ${ }^{*} 5$ reduced-functioning allele [26]. Among the three studies assessed in this review with a phenotype-genotype concordance of less than $70 \%$, one observed no separation in the distribution of its caffeine phenotyping results and the other two included the * 12 and ${ }^{*} 13$ variants $[37,44,45]$. As a result, our approach has been to adopt the 4-SNP model proposed by Hein et al. $[8,33]$. This 4 -SNP model includes the $* 5, * 6, * 7$, and ${ }^{*} 14$ alleles and shows equivalent NAT2 phenotyping concordance $(98.4 \%)$ compared to a 7-SNP model (98.4\%) with the ${ }^{*} 11,{ }^{*} 12$, and ${ }^{*} 13$ alleles included [33].

Among the 29 studies, there is clear evidence regarding the association between NAT2 phenotype and genotype. The 4-SNP model accurately predicts fast and slow acetylator status in multiple populations. This is important as early studies regarding hydralazine concentration, efficacy, and toxicity often determined acetylator status by phenotyping with a probe drug.

Genotype-Guided Hydralazine Therapy

\section{Effects of Predicted NAT2 Activity on Hydralazine Concentrations}

A preponderance of evidence supports the correlation between NAT2 enzyme activity (or its predictive genotype) and urine and plasma hydralazine concentrations (Table 2). This association has been shown in a diverse array of populations, with studies dating back to the early 1970s. The association has also been recognized in the FDA's Table of Pharmacogenetic Associations and mentioned in the drug labels of BiDil and Apresoline [4-6].

For example, in one study of 47 patients on maintenance hydralazine dosed at 50,100,150,200, or $300 \mathrm{mg}$ daily for the treatment of essential hypertension, a significant difference in the 3-hydroxymethyl-1,2,4-triazolo- $[3,4 a]$ phthalazine/acid-labile hydralazine ratio was found between fast and slow acetylators taking $100 \mathrm{mg}$ of hydralazine daily ( 7.3 to $2.3, p<0.01$ ) and $200 \mathrm{mg}$ of hydralazine daily (14.9 to $1.5, p<0.001$ ) [49]. These 47 individuals were phenotyped utilizing the sulfamethazine method, which identified 22 slow and 25 fast acetylators. The study concluded that the metabolism of hydralazine was dose dependent in fast acetylators, where higher doses resulted in greater acetylation of hydralazine.

In a similar study of 26 healthy male volunteers given a single dose of $182 \mathrm{mg}$ of controlled-release hydralazine, the area under the curve (AUC) and maximum concentration $\left(C_{\max }\right)$ of plasma hydralazine levels were significantly higher for slow acetylators than fast acetylators $(4,990.6 \pm 1,532.3$ vs. $2,233.6 \pm 663.5 \mathrm{ng} \mathrm{h} / \mathrm{mL}$ for AUC, and $470.4 \pm 162.8$ vs. $208.4 \pm 56.9 \mathrm{ng} / \mathrm{mL}$ for $C_{\max }$, respectively) [10]. Acetylator phenotype was determined using the sulfamethazine method, identifying 13 slow and 13 fast acetylators. The second part of this study focused on 85 cancer patients using the same phenotyping method, but dosed the patients based on acetylator status (fast acetylators receiving $182 \mathrm{mg}$ and slow acetylators receiving $83 \mathrm{mg}$ ). This $119 \%$ dose increase strategy was modeled upon the ratio of hydralazine AUC in the earlier healthy volunteer portion of this study. There were 37 slow and 48 fast acetylators in this population. Despite the over 2-fold difference in dose, the plasma hydralazine levels were similar between fast and slow acetylators $(239.1 \pm 81.7$ vs. $259.2 \pm 148.5 \mathrm{ng} /$ $\mathrm{mL}$ for mean concentration). This trial highlighted the importance of obtaining the acetylator phenotype and that the hydralazine-acetylator relationship remains, even in a special oncology population. 
Table 2. Summary of evidence: NAT2 phenotyping/genotyping relationship to hydralazine concentration, efficacy, and toxicity

\begin{tabular}{|c|c|c|c|c|}
\hline Category & Population (size) & Phenotype/genotype method & Major finding & Reference \\
\hline \multirow{24}{*}{$\begin{array}{l}\text { Genotype/ } \\
\text { phenotype } \\
\text { concordance }\end{array}$} & South African $(N=47)$ & Isoniazid/*5, *6, *7, ${ }^{*} 12, * 14$ & $100 \%$ concordance & {$[13]$} \\
\hline & Pakistani $(N=200)$ & Dapsone $/ * 5, * 6, * 7$ & $94 \%$ concordance & {$[20]$} \\
\hline & Ethiopian $(N=134)$ & Caffeine $/ * 5, * 6, * 7, * 14$ & $75.3 \%$ concordance & {$[21]$} \\
\hline & \multirow{2}{*}{$\begin{array}{l}\text { African American/Caucasian } \\
(N=42)\end{array}$} & Caffeine $/ * 5, * 6, * 7$ & $90 \%$ concordance & {$[23]$} \\
\hline & & Caffeine $/ * 5, * 6, * 7, * 14$ & $100 \%$ concordance & \\
\hline & Greenlandic $(N=143)$ & Caffeine $/ * 5, * 6, * 7, * 12$ & $86.7 \%$ concordance & {$[24]$} \\
\hline & German $(N=211)$ & Caffeine $/ * 5, * 6, * 7, * 12, * 13$ & $87.2 \%$ concordance & {$[25]$} \\
\hline & Latin American $(N=25)$ & Isoniazid $/ * 5, * 6, * 7$ & $88 \%$ concordance & {$[29]$} \\
\hline & Russian $(N=75)$ & Sulfadimidine $/ * 5, * 6, * 7, * 12, * 13$ & $87 \%$ concordance & {$[30]$} \\
\hline & European $(N=81)$ & Caffeine $/ * 5, * 6, * 7$ & $97.5 \%$ concordance & {$[31]$} \\
\hline & Caucasian $(N=255)$ & Caffeine $/ * 5, * 6, * 7,{ }^{*} 12, * 13$ & $97.8 \%$ concordance & {$[32]$} \\
\hline & \multirow{3}{*}{$\begin{array}{l}\text { African American/Asian/ } \\
\text { Caucasian/ Hispanic/ } \\
\text { Polynesian }(N=250)\end{array}$} & $\begin{array}{l}\text { Sulfamethazine } / * 5, * 6, * 7, * 11 \text {, } \\
{ }^{*} 12,{ }^{*} 13,{ }^{*} 14\end{array}$ & $98.4 \%$ concordance & {$[33]$} \\
\hline & & Sulfamethazine $/ * 5, * 6, * 7, * 14$ & $98.4 \%$ concordance & \\
\hline & & Sulfamethazine $/ * 6, * 7, * 11$ & $92.2 \%$ concordance & \\
\hline & Asian Indian $(N=251)$ & Isoniazid $/ * 5, * 6, * 7$ & $93 \%$ concordance & {$[38]$} \\
\hline & Caucasian $(N=38)$ & Caffeine $/ * 5, * 6, * 7,{ }^{*} 12, * 13$ & $100 \%$ concordance & [39] \\
\hline & Caucasian $(N=504)$ & Caffeine $/ * 5, * 6, * 14$ & $94 \%$ concordance & {$[40]$} \\
\hline & Polish $(N=63)$ & Isoniazid/*5, *6, *7 & $96.8 \%$ concordance & {$[41]$} \\
\hline & Polish $(N=39)$ & Isoniazid $/ * 6, * 7,{ }^{*} 11, * 12$ & $97 \%$ concordance & {$[42]$} \\
\hline & Swedish $(N=70)$ & Isoniazid $/ * 5, * 6, * 7$ & $100 \%$ concordance & {$[43]$} \\
\hline & Hmong $(N=51)$ & Caffeine $/ * 5, * 6, * 7, * 13$ & $14 \%$ concordance & {$[44]$} \\
\hline & French $(N=76)$ & Caffeine $/ * 5, * 6, * 7,{ }^{*} 12, * 13, * 14$ & $65 \%$ concordance & {$[45]$} \\
\hline & Emirati $(N=106)$ & Caffeine $/ * 5, * 6, * 7, * 14$ & $98.1 \%$ concordance & {$[46]$} \\
\hline & Chinese $(N=103)$ & Caffeine $/ * 5, * 6, * 7$ & $98.1 \%$ concordance & [47] \\
\hline
\end{tabular}


Table 2 (continued)

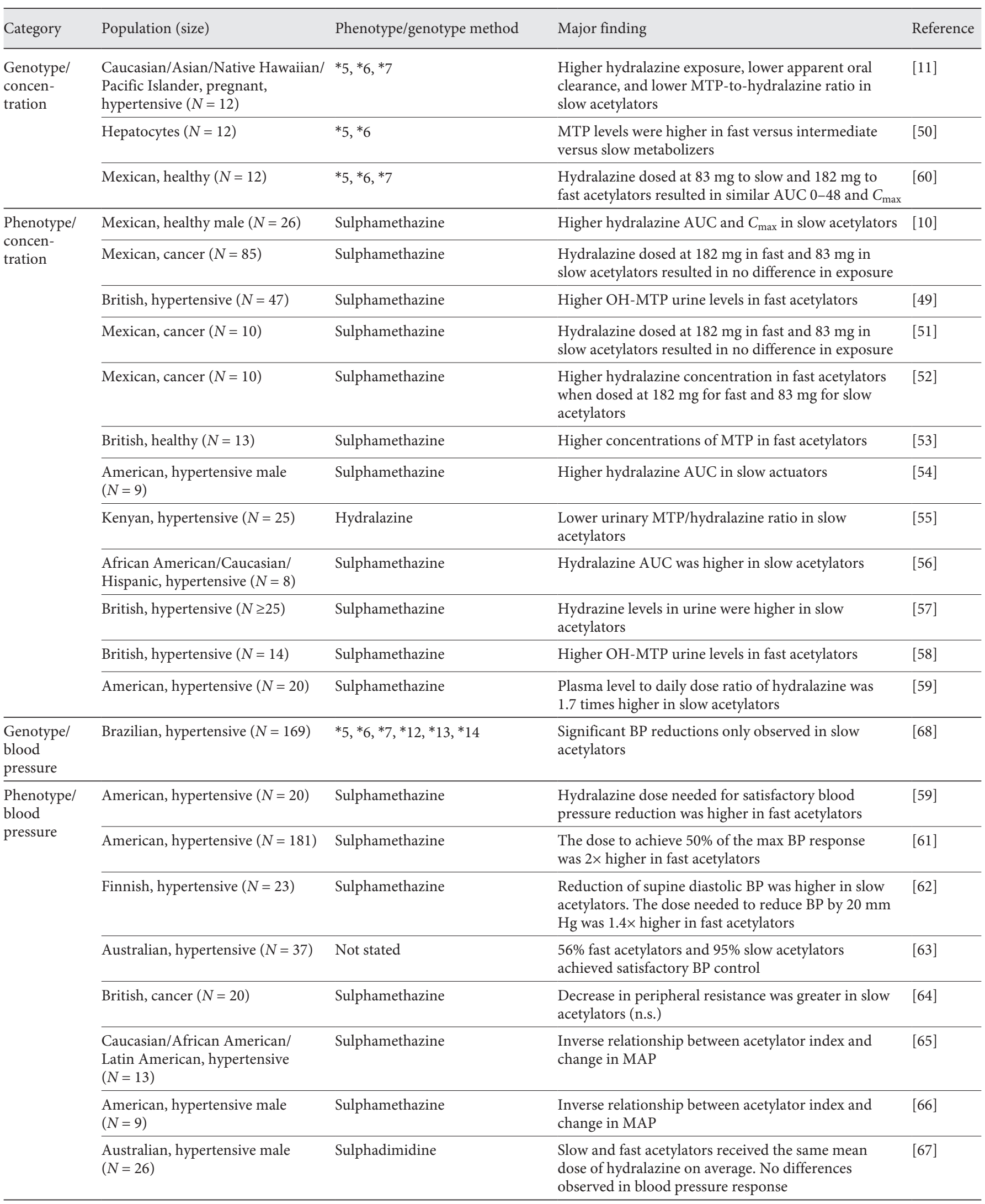


Table 2 (continued)

\begin{tabular}{|c|c|c|c|c|}
\hline Category & Population (size) & Phenotype/genotype method & Major finding & Reference \\
\hline $\begin{array}{l}\text { Toxicity/ } \\
\text { genotype }\end{array}$ & Brazilian, hypertensive $(N=169)$ & ${ }^{*} 5,{ }^{*} 6,{ }^{*} 7,{ }^{*} 12,{ }^{*} 13,{ }^{*} 14$ & $\begin{array}{l}\text { Three out of } 4 \text { patients withdrawn from hydralazine } \\
\text { due to side effects were slow acetylators. One slow } \\
\text { acetylator with SLE-like syndrome }\end{array}$ & {$[68]$} \\
\hline \multirow[t]{6}{*}{$\begin{array}{l}\text { Toxicity/ } \\
\text { phenotype }\end{array}$} & $\begin{array}{l}\text { Mexican, healthy male }(N=26) \text {, } \\
\text { cancer }(N=85)\end{array}$ & Sulphamethazine & $\begin{array}{l}\text { Healthy slow acetylators developed side effects. } \\
\text { Cancer slow acetylators received a lower dose based } \\
\text { on healthy individuals, and no side effects were } \\
\text { observed }\end{array}$ & {$[10]$} \\
\hline & Australian, hypertensive $(N=37)$ & Not stated & Adverse events only observed in slow acetylators & {$[63]$} \\
\hline & Australian, hypertensive $(N=26)$ & Sulphadimidine & One slow acetylator developed a lupus-like rash & {$[67]$} \\
\hline & $\begin{array}{l}\text { Caucasian, hydralazine-induced } \\
\text { lupus }(N=26)\end{array}$ & Sulphamethazine & $\begin{array}{l}\text { Majority of hydralazine-induced lupus cases were } \\
\text { slow acetylators and female }\end{array}$ & [70] \\
\hline & British, hypertensive $(N=281)$ & Not stated & $\begin{array}{l}\text { Higher incidence of SLE in slow acetylators and } \\
\text { women taking hydralazine }\end{array}$ & [71] \\
\hline & $\begin{array}{l}\text { Caucasian, hypertensive female } \\
(N=6)\end{array}$ & Not stated & All 6 women were slow acetylators and developed SLE & {$[72]$} \\
\hline
\end{tabular}

MAP, mean arterial pressure; SLE, systemic lupus erythematosus; NAT2, N-acetyltransferase 2; AUC, area under the curve; MTP, 3-methyl-1,2,4-triazolo-[3,4a] phthalazine; 3OH-MTP, 3-hydroxymethyl-1,2,4-triazolo-[3,4a] phthalazine.

A more recent study included 12 pregnant women treated for essential hypertension taking 5-25 mg of hydralazine every $6 \mathrm{~h}[11]$. Acetylator status was determined using NAT2 genotyping of the $* 4, * 5, * 6$, and $* 7$ alleles. These patients consisted of 3 slow and 2 fast acetylators in the second trimester, and 3 slow and 4 fast acetylators in the third trimester. Results revealed that dose-normalized AUC and $C_{\max }$ hydralazine concentrations were higher in slow acetylators than fast acetylators (AUC: $5.9 \pm 3.7$ vs. $1.5 \pm 0.8 \mathrm{ng} \mathrm{h} / \mathrm{mL}, C_{\max }$ : $4.04 \pm 3.18$ vs. $0.77 \pm 0.51 \mathrm{ng} / \mathrm{mL}$ ). The inverse was observed for MTP concentrations, with fast acetylators having a higher dose-normalized AUC and $C_{\max }$ of the metabolite than slow acetylators (AUC: $118.1 \pm 64.9$ vs. $56.4 \pm 40.7 \mathrm{ng} \mathrm{h} / \mathrm{mL}, C_{\max }: 32.3 \pm 11.7$ vs. $15.0 \pm 8.8$ $\mathrm{ng} / \mathrm{mL}$ ). Thus, acetylation status remains relevant in pregnancy.

The three studies above suggest that evidence supports an association between acetylator phenotype or genotype and hydralazine concentrations. Similar findings were observed in other populations: Asian, African American, British, Kenyan, Mexican, Native Hawaiian, and Pacific Islanders (Table 2) [50-60]. Thus, a consistent and significant relationship between acetylator status and hydralazine concentration exists across a spectrum of populations.

\section{Effects of Predicted NAT2 Activity on Hydralazine Efficacy}

A smaller subset of studies offer evidence beyond pharmacokinetics, finding that an individual's NAT2 genotype or phenotype also predicts the antihypertensive efficacy of hydralazine (Table 2) [59, 61-68]. These studies either show that (1) hydralazine is a more effective antihypertensive in slow acetylators than fast acetylators or (2) a higher dose is required to achieve equivalent efficacy in fast acetylators. Overall, the direction of effect of these studies is in agreement, providing a clear association between acetylator status and therapeutic response from hydralazine.

In a 1972 study of 20 subjects with moderate to severe hypertension treated with a combination of hydralazine, hydrochlorothiazide, and propranolol, the plasma concentration of hydralazine and blood pressure were both associated with NAT2 phenotype [59]. The sulfamethazine method identified 13 slow and 7 fast acetylators. Slow acetylators were shown to have a higher mean plasma hydralazine concentration $(5.1 \mu \mathrm{g} / \mathrm{mL})$ than fast acetylators $(3.0$ $\mu \mathrm{g} / \mathrm{mL}$ ) on a daily dose of $1.5 \mathrm{mg} / \mathrm{kg}$. The hydralazine dosenormalized plasma concentrations were calculated to be 1.7-fold higher in slow acetylators than fast acetylators $(p<0.005)$. These hydralazine plasma levels positively correlated with a reduction in supine mean arterial pressure 
(MAP) $(p<0.01)$. Ultimately, the study determined that when hydralazine was administered with the two other blood pressure medications, satisfactory blood pressure control was achieved with a mean dose of $2.4 \mathrm{mg} / \mathrm{kg} / \mathrm{day}$ in slow acetylators and $3.7 \mathrm{mg} / \mathrm{kg} /$ day in fast acetylators.

A second study reached similar conclusions regarding combination regimens containing hydralazine [63]. Thirty-seven subjects were randomized into a double-blind crossover study to validate the efficacy of hydralazine in combination therapy. The phenotyping method in this study was not disclosed. However, only 5 of 9 fast acetylators achieved satisfactory blood pressure control compared to 19 of the 20 slow acetylators $(p<0.02)$. Of note, 8 of the slow acetylators developed side effects attributable to hydralazine, whereas no side effects were observed in the 9 fast acetylators $(p=0.028)$.

In a third study of 25 patients with mild to moderate essential hypertension on hydralazine combination therapy, phenotype was determined by the sulfamethazine method [62]. Results showed a correlation between daily doses of hydralazine and plasma hydralazine levels in both slow acetylators $(r=0.480)$ and fast acetylators $(r=$ $0.580)$. A significant reduction of supine diastolic blood pressure was greater in slow acetylators $(23 \mathrm{~mm} \mathrm{Hg}$ ) than fast acetylators $(15 \mathrm{~mm} \mathrm{Hg})(p<0.05)$. The investigators also determined that the dose required to reduce supine systolic blood pressure by $20 \mathrm{~mm} \mathrm{Hg}$ in slow acetylators was $1.0 \mathrm{mg} / \mathrm{kg}$, equivalent to $1.4 \mathrm{mg} / \mathrm{kg}$ in fast acetylators.

The antihypertensive response to hydralazine following administration by both the oral and IV routes has been investigated in a pair of studies using the sulfamethazine method to determine phenotype. The initial phase of the study was a longitudinal observational study of 9 patients with essential hypertension on oral hydralazine [66]. It then followed up these 9 individuals with singledose and multiple-dose oral hydralazine, both dosing hydralazine at $1 \mathrm{mg} / \mathrm{kg}$. The study reported that there was an inverse relationship between acetylator index and the change in MAP following both single $(p<0.05)$ and multiple oral doses of hydralazine $(p<0.01)$. The study concluded that among these 9 individuals, the acetylator phenotype was a major determinant of response and that plasma concentrations of hydralazine were lower in fast than slow acetylator phenotype patients. A second phase of this study evaluated IV hydralazine response in 13 individuals [65], finding a similar inverse correlation between acetylator index and the change in MAP $(r=$ $-0.6168, p<0.05)$.

In the largest study of NAT2 phenotype and antihypertensive response to hydralazine, 181 subjects across 5 different sites were divided into groups taking immediate-release hydralazine or extended-release hydralazine [61]. Phenotype was determined using the sulfamethazine method. Their modeling indicated that the daily dose that elicited $50 \%$ of the maximum response was $0.87 \mathrm{mg} /$ $\mathrm{kg}$ for slow acetylators and $1.68 \mathrm{mg} / \mathrm{kg}$ for fast acetylators. Extended hydralazine therapy was estimated to reduce blood pressure by $0.524 \mathrm{~mm} \mathrm{Hg}$ per week or roughly 4 $\mathrm{mm} \mathrm{Hg}$ over a 7-week period. In combination with a $\beta$-blocker and diuretic, the blood pressure reduction increased to $6.54 \mathrm{~mm} \mathrm{Hg}$.

The only study to specifically address the relationship of NAT2 genotype and antihypertensive response was a Brazilian study of 169 subjects already taking hydralazine to control resistant hypertension [68]. These patients were genotyped for the $* 4,{ }^{*} 5,{ }^{*} 6,{ }^{*} 7,{ }^{*} 12,{ }^{*} 13$, and ${ }^{*} 14$ alleles in order to determine acetylator status. The genotyping resulted in 65 (38.5\%) intermediate, 60 (35.5\%) slow, and $21(12.4 \%)$ fast acetylators in the population. The remaining patients were indeterminate. Significant reductions in blood pressure were only observed in the slow acetylators. The mean 24 -h systolic and diastolic reductions in slow acetylators were 9.2 and $5.5 \mathrm{~mm} \mathrm{Hg}$, respectively, and clinic blood pressures were reduced by 18.6 $\mathrm{mm} \mathrm{Hg}$ systolic and $8.8 \mathrm{~mm} \mathrm{Hg}$ diastolic. Moreover, it was concluded that hydralazine reduced both daytime and night-time blood pressure equally.

The evidence from 7 identified studies reveals an association between an individual's NAT2 phenotype or genotype and hydralazine efficacy (Table 2). One small study did not reach significance, but the observed effect on peripheral vascular resistance was still consistent with the expected direction of effect [64]. A second study observed no difference in blood pressure control among individuals who received the same hydralazine dose on average [67]. Additional studies which directly compare genotype to antihypertensive response would be valuable to confirm this relationship since most studies utilize NAT2 phenotype rather than genotype.

\section{Hydralazine and Heart Failure}

The 2 main indications for hydralazine are essential hypertension and the management of heart failure with a reduced ejection fraction (HFrEF), the latter in conjunction with isosorbide dinitrate (BiDil). BiDil has been shown to be highly effective in the treatment of HFrEF in the African American population [7]. There are no direct studies comparing NAT2 acetylator status with HFrEF 
outcomes. However, race may be a surrogate of reduced acetylator status. African Americans have a higher frequency of the NAT2* 5 and 14 genotypes, which may in part explain the efficacy of hydralazine in this population. The minor allele frequency for NAT2*5 is 0.43 and that for $N A T 2^{*} 14$ is 0.004 in the general population, but 0.67 and 0.08 , respectively, in individuals of African ancestry (Table 1) [69].

\section{Hydralazine-Related Toxicities}

The common side effects of hydralazine are primarily associated with the drug's mechanism of action and efficacy (Table 2) $[10,63,68,70-72]$. As a potent arterial vasodilator, side effects such as headache, reflex tachycardia, and/or angina pectoris are commonly reported by patients who are exposed to hydralazine. In addition, systemic lupus erythematosus (SLE) is reported infrequently but has potential serious and long-term consequences.

Patients with the NAT2 slow acetylator phenotype are exposed to an increased concentration of the parent compound, putting them at increased risk for adverse effects. For example, healthy volunteers who were phenotyped as slow acetylators and administered a single dose of $182 \mathrm{mg}$ of hydralazine experienced adverse effects ranging from mild headaches to fainting that required supplemental oxygen. Volunteers who were phenotyped as fast acetylators did not report any side effects. A lower dose of 83 $\mathrm{mg} /$ day administered to slow acetylator patients was well tolerated with no reported side effects or SLE after 1 year in the dose-adjusted group [10].

To reduce the risk of hydralazine adverse effects, it has been recommended to co-prescribe a $\beta$-blocker and/or diuretic to help with reflex tachycardia and fluid retention [73]. However, patients optimized on this double or triple therapy still experienced side effects, including palpitations, among others. Patients who were phenotyped as slow acetylators $(n=20)$ had a higher incidence of adverse events than those who were phenotyped as fast acetylators $(n=9)$ ( 40 vs. $0 \% ; p=0.028)$ [63].

\section{Systemic Lupus Erythematosus}

Reports associating SLE with hydralazine emerged less than 1 year after drug approval $[12,74]$. SLE is now included as a warning in the hydralazine drug label $[4,5]$. It has been hypothesized that patients with the NAT2 slow acetylator phenotype have an increased risk of developing idiopathic SLE, even without a known aggravating agent such as hydralazine. However, this hypothesis has not been consistently supported. For example, a case-control study of 209 ( 194 women, 15 men) patients with SLE and 209 sex-matched patients without SLE documented a SLE prevalence of $59.8 \%$ among NAT2 slow acetylators and $56.5 \%$ among those without the NAT2 slow acetylator phenotype $(p=0.45)$, suggesting the NAT2 acetylator phenotype alone was not associated with idiopathic SLE [75]. The lack of association has been further confirmed in multiple publications since then $[41,76,77]$. Thus, the evidence does not support an increased risk of SLE in slow acetylators without exposure to an aggravating agent; however, these studies should not be conflated with studies of hydralazine-induced lupus.

In contrast, there is evidence that suggests greater hydralazine exposure increases the risk of drug-induced lupus $[67,68,70-72]$. This increased exposure may be due to either higher doses of hydralazine or a slow acetylator status which increases circulating concentrations. First, hydralazine dose has been associated with the development of SLE in slow acetylators. A study of 281 patients who were followed up over 3 years had no reports of SLE when the total daily hydralazine dose was $50 \mathrm{mg}$. However, when the dose was increased to $100 \mathrm{mg}$ a day, SLE was reported in $5.4 \%$ of patients, and among patients exposed to $200 \mathrm{mg}$ daily, SLE was reported in $10.4 \%$ of patients. Among the patients who developed SLE $(n=14 ; 10$ women, 4 men), 11 were slow acetylators, 2 had unknown phenotype, and 1 was a fast acetylator. Of note, 4 patients with the fast acetylator phenotype were exposed to 400 $\mathrm{mg}$ a day, which is above the FDA-recommended maximum dose of $300 \mathrm{mg}$, and SLE was not reported in any of them, further supporting the association of slow acetylator phenotype and the risk of SLE [71].

Sex may also play a role in the incidence of SLE among those with the slow acetylator phenotype, compared with fast acetylators. Among 26 patients who developed SLE after being exposed to hydralazine, $96 \%$ were phenotyped as slow acetylators [70]. The SLE group was compared to 16 slow acetylator patients who did not develop SLE while on hydralazine for 1 year to determine if sex, acetylator phenotype, and HLA-DR4 increased the risk of developing SLE. Women developed SLE in $80 \%$ of cases compared to $31 \%$ of males $(p<0.01)$. The 5 men who developed SLE were DR4+ and on $200 \mathrm{mg}$ of hydralazine. Women developed SLE regardless of being DR4+ and dose [70]. A case series of 6 patients who developed lupus nephritis after exposure to hydralazine supports the association of sex, SLE, and NAT2 acetylator phenotype. All 
Table 3. Hydralazine dosing recommendations for the indication of resistant hypertension

\begin{tabular}{|c|c|}
\hline NAT2 status & Recommendation \\
\hline $\begin{array}{l}\text { Intermediate }^{\mathrm{a}} \\
\text { or fast }^{\mathrm{b}} \\
\text { acetylator }\end{array}$ & $\begin{array}{l}\text { Predicted to have reduced hydralazine efficacy; } \\
\text { consider a } 50-100 \% \text { higher starting dose of } \\
\text { hydralazine for patients with resistant } \\
\text { hypertension. Limit total daily hydralazine dose } \\
\text { to } 300 \mathrm{mg} \text { daily }\end{array}$ \\
\hline $\begin{array}{l}\text { Slow } \\
\text { acetylator }^{c}\end{array}$ & $\begin{array}{l}\text { Predicted to have increased hydralazine levels, } \\
\text { which may lead to increased efficacy and/or } \\
\text { adverse effects. Use caution with total daily } \\
\text { hydralazine doses of } 200 \mathrm{mg} \text { or more }\end{array}$ \\
\hline
\end{tabular}

NAT2, N-acetyltransferase 2. ${ }^{\text {a }}$ Intermediate acetylators have 1 copy of a reduced-functioning allele. ${ }^{\mathrm{b}}$ Fast acetylators have no copies of a reduced-functioning allele. ${ }^{c}$ Slow acetylators have 2 copies of a reduced-functioning allele.

6 patients were Caucasian females and phenotyped as slow acetylators. The hydralazine dose ranged from 50 to $300 \mathrm{mg}$ daily for a duration ranging from 6 months to 7 years. In all patients, discontinuation of hydralazine and immunosuppressive therapy abated symptoms of lupus nephritis, as is expected in the setting of drug-induced SLE $[72,78]$.

In the Brazilian study of NAT2 genotype and blood pressure response discussed above, 4 of 169 (2.4\%) patients withdrew from the study due to adverse events. Of those, 3 were slow acetylators, and 1 slow acetylator developed a lupus-like syndrome [68]. Based on the available literature, hydralazine exposure and the NAT2 slow acetylator phenotype are potential risk factors for the development of adverse events, including drug-induced SLE. Female sex and HLA-DR4+ may further increase the risk for SLE. As a result, several societies have called to limit maximum hydralazine exposure [73]. Since there are only a small number of total hydralazine-induced lupus cases reported, additional studies are warranted to confirm the association between NAT2 activity and hydralazine-induced lupus.

\section{Hydralazine Dosing Recommendation}

Recommendations for genotype-guided hydralazine therapy are included in Table 3. The allele frequency distribution of NAT2 in the general population yields an approximately 50/50 split in slow acetylators versus intermediate or fast acetylators. As a result, there is no major-

Genotype-Guided Hydralazine Therapy ity phenotype to serve as a benchmark in the general population. Thus, all individuals regardless of acetylation status could benefit from personalized prescribing of hydralazine to optimize dosing and therapy selection. Individuals with a fast acetylator phenotype are likely to benefit from a higher starting dose or faster titration of hydralazine than slow acetylators. In the cited literature, the requisite dose increase in fast acetylators ranges from 40 to $125 \%$ to match hydralazine concentrations in slow acetylators. Most studies suggest a 50-100\% higher dose is appropriate in fast acetylators.

At present, intermediate acetylators are grouped with fast acetylators with regard to dosing recommendations. In over 4,000 individuals, the majority of phenotyping studies display a bimodal distribution of NAT2 activity. A minority of phenotyping studies does reveal an intermediate phenotype, and it is possible that a more consistent and clinically relevant intermediate phenotype would emerge with additional subjects who are carefully phenotyped for acetylator status and antihypertensive response [13, 14, 33].

Slow acetylators can similarly benefit from genotypeguided therapy by restricting the total daily dose to reduce the incidence of adverse events. As more evidence emerges, it may be necessary to restrict maximum doses even further in very slow acetylators with two * 6 or *7 alleles $[26,40,48]$. At present, there is still limited but consistent evidence linking hydralazine exposure to drug-induced SLE. Other predictors such as gender and HLA-DR4 genotype are concomitant risk factors for SLE. While the FDA has approved total daily doses up to $300 \mathrm{mg} /$ day, the American College of Cardiology (ACC) and American Heart Association (AHA) have suggested limiting total daily doses to $200 \mathrm{mg}$ /day to reduce the risk of a lupuslike reaction [73]. NAT2 genotype can reliably predict higher systemic concentrations and may allow clinicians to make informed decisions on whether to titrate hydralazine to doses above $200 \mathrm{mg} /$ day. Slow acetylators could have their total dose limited to less than $200 \mathrm{mg} /$ day or have an alternative vasodilatory drug prescribed. Fast and intermediate acetylators could be titrated to $300 \mathrm{mg} /$ day in the setting of severe resistant hypertension. Regardless, clinicians should monitor for signs and symptoms of lupus in all of their patients treated with hydralazine.

\section{Conclusion and Future Directions}

In summary, we present evidence supporting several associations between NAT2 genotype and relevant hydralazine phenotypes. The strongest of these associations 
is between the NAT2 enzyme activity phenotype and NAT2 genotype. This link between phenotype and genotype is critical as a large portion of hydralazine studies were conducted in an era before the human genome was sequenced. We identified fourteen studies which support the association between either NAT2 phenotype or genotype and hydralazine concentration. Seven additional studies link NAT2 acetylator status to hydralazine efficacy. What is remarkable is the relative paucity of studies that present contradictory evidence. We identified three investigations in Table 2 that tested the association of NAT2 phenotype with hydralazine concentration or blood pressure which failed to reach statistical significance or achieve the expected outcome [52, 64, 67]. Although these three studies were not significant, the expected direction of effect among acetylator status, concentration, and efficacy was maintained.

The association of NAT2 phenotype with hydralazineinduced lupus is less evident as few studies have been designed to assess adverse events. It is more apparent that SLE is not associated with NAT2 phenotype in the absence of hydralazine. Given the uncommon and multifactorial nature of drug-induced lupus, many studies will be underpowered to detect an effect. Additional risk factors such as hydralazine dose, HLA-DR4 status, and gender also contribute to drug-induced lupus. Nonetheless, major societies (ACC/AHA) have recommended limiting hydralazine exposure to reduce the risk of drug-induced lupus $[73,79]$. Thus, the stronger evidence that links NAT2 acetylator status to hydralazine concentration provides indirect evidence that slow acetylators may benefit from lower total daily doses of hydralazine to reduce the risk of drug-induced lupus.

The National Human Genome Research Institute's Implementing Genomics in Practice (IGNITE) consortium seeks to test the value of implementing genomic in- formation into clinical care through pragmatic clinical trials. As part of an upcoming trial called the Genetic testing to Understand and Address Renal Disease Disparities in the USA (GUARDD-US) study (NCT04191824), approximately 6,000 individuals will be genotyped for NAT2, including those with resistant hypertension prescribed hydralazine. This pragmatic study will help understand the relationship between NAT2 genotype, blood pressure, and adverse events in a real-world setting.

\section{Acknowledgements}

The authors are grateful to Todd C. Skaar, John T. Callaghan, and Zeruesenay Desta for their advice and counsel.

\section{Conflict of interest Statement}

The authors have no conflicts of interest to disclose.

\section{Funding Sources}

Support for this work was provided by the NIH/NIDDK K08DK107864 (MTE), NIH/NHGRI U01HG010245 (MTE), NIH/NHGRI U01HG007269 (RMCD), and NIH/NIGMS T32GM008425 (ALJR). KSC was supported by the Indiana University School of Medicine Grand Challenge Fund 1705413046.

\section{Author Contributions}

The contributions of the authors to this work include the following: library search and identification of articles: K.S.C., A.L.E., and M.T.E.; summarization of articles: K.S.C., A.L.J.R., A.M.W., A.L.E., and Y.Z.; manuscript writing, drafting, and revising: all authors; and conception: K.S.C., R.M.C.D., and M.T.E.

\section{References}

1 Carey RM, Calhoun DA, Bakris GL, Brook RD, Daugherty SL, Dennison-Himmelfarb CR, et al. Resistant hypertension: detection, evaluation, and management: a scientific statement from the american heart association. Hypertension. 2018;72(5):e53-90.

2 McDonagh EM, Boukouvala S, Aklillu E, Hein DW, Altman RB, Klein TE. PharmGKB summary: very important pharmacogene information for $\mathrm{N}$-acetyltransferase 2. Pharmacogenet Genomics. 2014;24(8):409-25.

3 NCBI. https://www.ncbi.nlm.nih.gov/gtr/all/ tests/?term $=10$ [geneid.
4 Arbor Pharmaceuticals LLC. https://www.accessdata.fda.gov/drugsatfda_docs/ label/2019/020727s010lbl.pdf.

5 Novartis. https://www.accessdata.fda.gov/ drugsatfda_docs/label/1996/008303s068lbl. pdf.

6 FDA. https://www.fda.gov/medical-devices/ precision-medicine/table-pharmacogeneticassociations.

7 Taylor AL, Ziesche S, Yancy C, Carson P, D'Agostino R Jr, Ferdinand K, et al. Combination of isosorbide dinitrate and hydralazine in blacks with heart failure. N Engl J Med. 2004;351(20):2049-57.
8 Collins KS, Pratt VM, Stansberry WM, Medeiros EB, Kannegolla K, Swart M, et al. Analytical validity of a genotyping assay for use with personalized antihypertensive and chronic kidney disease therapy. Pharmacogenet Genomics. 2019;29(1):18-22.

9 Spiech KM, Tripathy PR, Woodcock AM Sheth NA, Collins KS, Kannegolla K, et al. Implementation of a renal precision medicine program: clinician attitudes and acceptance. Life. 2020;10(4):32. 
10 Gonzalez-Fierro A, Vasquez-Bahena D, TajaChayeb L, Vidal S, Trejo-Becerril C, PérezCardenas E, et al. Pharmacokinetics of hydralazine, an antihypertensive and DNA-demethylating agent, using controlled-release formulations designed for use in dosing schedules based on the acetylator phenotype. Int J Clin Pharmacol Ther. 2011;49(8):51924.

11 Han LW, Ryu RJ, Cusumano M, Easterling TR, Phillips BR, Risler LJ, et al. Effect of NAcetyltransferase 2 genotype on the pharmacokinetics of hydralazine during pregnancy. J Clin Pharmacol. 2019;59(12):1678-89.

12 Weber WW, Hein DW. N-acetylation pharmacogenetics. Pharmacol Rev. 1985;37(1): 25-79.

13 Parkin DP, Vandenplas S, Botha FJ, Vandenplas ML, Seifart HI, van Helden PD, et al. Trimodality of isoniazid elimination: phenotype and genotype in patients with tuberculosis. Am J Respir Crit Care Med. 1997;155(5): 1717-22.

14 Le Marchand L, Sivaraman L, Franke AA, Custer LJ, Wilkens LR, Lau AF, et al. Predictors of $\mathrm{N}$-acetyltransferase activity: should caffeine phenotyping and NAT2 genotyping be used interchangeably in epidemiological studies? Cancer Epidemiol Biomarkers Prev. 1996;5(6):449-55.

15 Weinshilboum R, Wang L. Pharmacogenomics: bench to bedside. Nat Rev Drug Discov. 2004;3(9):739-48.

16 Grant DM, Mörike K, Eichelbaum M, Meyer UA. Acetylation pharmacogenetics. The slow acetylator phenotype is caused by decreased or absent arylamine $\mathrm{N}$-acetyltransferase in human liver. J Clin Invest. 1990;85(3):96872.

17 Harris HW, Knight RA, Selin MJ. Comparison of isoniazid concentrations in the blood of people of Japanese and European descent; therapeutic and genetic implications. Am Rev Tuberc. 1958;78(6):944-8.

18 Evans DA, Manley KA, McKUSICK VA. Genetic control of isoniazid metabolism in man. Br Med J. 1960;2(5197):485-91.

19 Mitchell RS, Bell JC. Clinical implications of isoniazid, PAS and streptomycin blood levels in pulmonary tuberculosis. Trans Am Clin Climatol Assoc. 1957;69(22):98-5.

20 Akhter N, Iqbal T, Jamil A, Akram M, Mehmood Tahir I, Munir N. Determination of arylamine $\mathrm{N}$-acetyltransferase 2 acetylation genotype by PCR and phenotyping using dapsone through high-pressure liquid chromatography assay: a gender wise study. Dose Response. 2019;17(2):1559325819855537.

21 Aklillu E, Carrillo JA, Makonnen E, Bertilsson L, Djordjevic N. N-Acetyltransferase-2 (NAT2) phenotype is influenced by genotype-environment interaction in ethiopians. Eur J Clin Pharmacol. 2018;74(7):903-11.
22 Al-Ahmad MM, Amir N, Dhanasekaran S, John A, Abdulrazzaq YM, Ali BR, et al. Studies on $\mathrm{N}$-acetyltransferase (NAT2) genotype relationships in emiratis: confirmation of the existence of phenotype variation among slow acetylators. Ann Hum Genet. 2017;81(5): 190-6.

23 Bell DA, Taylor JA, Butler MA, Stephens EA, Wiest J, Brubaker LH, et al. Genotype/ phenotype discordance for human arylamine $\mathrm{N}$-acetyltransferase (NAT2) reveals a new slow-acetylator allele common in African-Americans. Carcinogenesis. 1993; 14(8):1689-92.

24 Birch Kristensen E, Yakimov V, BjornMortensen K, Soborg B, Koch A, Andersson $\mathrm{M}$, et al. Study of correlation between the NAT2 phenotype and genotype status among greenlandic inuit. EXCLI J. 2018;17:1043-53.

25 Bolt HM, Selinski S, Dannappel D, Blaszkewicz M, Golka K. Re-investigation of the concordance of human NAT2 phenotypes and genotypes. Arch Toxicol. 2005;79(4):196200.

26 Cascorbi I, Drakoulis N, Brockmöller J, Maurer A, Sperling K, Roots I. Arylamine N-acetyltransferase (NAT2) mutations and their allelic linkage in unrelated Caucasian individuals: correlation with phenotypic activity. Am J Hum Genet. 1995;57(3):581-92.

27 Cascorbi I, Brockmöller J, Mrozikiewicz PM, Müller A, Roots I. Arylamine N-acetyltransferase activity in man. Drug Metab Rev. 1999; 31(2):489-502.

28 Deguchi T, Mashimo M, Suzuki T. Correlation between acetylator phenotypes and genotypes of polymorphic arylamine $\mathrm{N}$-acetyltransferase in human liver. J Biol Chem. 1990; 265(22):12757-60.

29 Díaz-Molina R, Cornejo-Bravo JM, RamosIbarra MA, Estrada-Guzmán JD, MoralesArango O, Reyes-Báez R, et al. Genotype and phenotype of NAT2 and the occurrence of adverse drug reactions in Mexican individuals to an isoniazid-based prophylactic chemotherapy for tuberculosis. Mol Med Rep. 2008; 1(6):875-9.

30 Goldenkova-Pavlova IV, Bruskin SA, Abdeev RM, Markarova EV, Bigvava SG, Radkevich $\mathrm{LA}$, et al. [Comparative analysis of $\mathrm{N}$-acetylation polymorphism in humans as determined by phenotyping and genotyping]. Genetika. 2006;42(8):1143-50.

31 Graf T, Broly F, Hoffmann F, Probst M, Meyer UA, Howald H. Prediction of phenotype for acetylation and for debrisoquine hydroxylation by DNA-tests in healthy human volunteers. Eur J Clin Pharmacol. 1992;43(4): 399-403.

32 Gross M, Kruisselbrink T, Anderson K, Lang N, McGovern P, Delongchamp R, et al. Distribution and concordance of $\mathrm{N}$-acetyltransferase genotype and phenotype in an American population. Cancer Epidemiol Biomarkers Prev. 1999;8(8):683-92.
33 Hein DW, Doll MA. Accuracy of various human NAT2 SNP genotyping panels to infer rapid, intermediate and slow acetylator phenotypes. Pharmacogenomics. 2012;13(1):3141.

34 Hickman D, Sim E. N-acetyltransferase polymorphism. Comparison of phenotype and genotype in humans. Biochem Pharmacol. 1991;42(5):1007-14.

35 Kaufmann GR, Wenk M, Taeschner W, Peterli B, Gyr K, Meyer UA, et al. N-acetyltransferase 2 polymorphism in patients infected with human immunodeficiency virus. Clin Pharmacol Ther. 1996;60(1):62-7.

36 Kuhn UD, Anschütz M, Schmücker K, Schug BS, Hippius M, Blume HH. Phenotyping with sulfasalazine: time dependence and relation to NAT2 pharmacogenetics. Int J Clin Pharmacol Ther. 2010;48(1):1-10.

37 O’Neil WM, Gilfix BM, DiGirolamo A, Tsoukas CM, Wainer IW. N-acetylation among HIV-positive patients and patients with AIDS: when is fast, fast and slow, slow? Clin Pharmacol Ther. 1997;62(3):261-71.

38 Rana SV, Ola RP, Sharma SK, Arora SK, Sinha SK, Pandhi P, et al. Comparison between acetylator phenotype and genotype polymorphism of n-acetyltransferase- 2 in tuberculosis patients. Hepatol Int. 2012;6(1):397-402.

39 Rihs HP, John A, Scherenberg M, Seidel A, Brüning T. Concordance between the deduced acetylation status generated by highspeed: real-time PCR based NAT2 genotyping of seven single nucleotide polymorphisms and human NAT2 phenotypes determined by a caffeine assay. Clin Chim Acta. 2007;376(12):240-3.

40 Ruiz JD, Martínez C, Anderson K, Gross M, Lang NP, García-Martín E, et al. The differential effect of NAT2 variant alleles permits refinement in phenotype inference and identifies a very slow acetylation genotype. PLoS One. 2012;7(9):e44629.

41 Rychlik-Sych M, Skretkowicz J, GawrońskaSzklarz B, Górnik W, Sysa-Jedrzejowska A, Skretkowicz-Szarmach K. Acetylation genotype and phenotype in patients with systemic lupus erythematosus. Pharmacol Rep. 2006; 58(1):22-9.

42 Skretkowicz K, Skretkowicz J, GawrońskaSzklarz B, Górnik W, Rychlik-Sych M, SysaJedrzejowska A. Lack of association between arylamine $\mathrm{N}$-acetyltransferase 2 (NAT2) polymorphism and systemic sclerosis. Eur J Clin Pharmacol. 2005;60(11):773-8.

43 Smith CA, Wadelius M, Gough AC, Harrison DJ, Wolf CR, Rane A. A simplified assay for the arylamine $\mathrm{N}$-acetyltransferase 2 polymorphism validated by phenotyping with isoniazid. J Med Genet. 1997;34(9):758-60.

44 Straka RJ, Burkhardt RT, Lang NP, Hadsall KZ, Tsai MY. Discordance between N-acetyltransferase 2 phenotype and genotype in a population of Hmong subjects. J Clin Pharmacol. 2006;46(7):802-11. 
45 Wolkenstein P, Loriot MA, Aractingi S, Cabelguenne A, Beaune P, Chosidow O. Prospective evaluation of detoxification pathways as markers of cutaneous adverse reactions to sulphonamides in AIDS. Pharmacogenetics. 2000;10(9):821-8.

46 Woolhouse NM, Qureshi MM, Bastaki SM, Patel M, Abdulrazzaq Y, Bayoumi RA. Polymorphic N-acetyltransferase (NAT2) genotyping of emiratis. Pharmacogenetics. 1997; 7(1):73-82.

47 Zhao B, Seow A, Lee EJ, Lee HP. Correlation between acetylation phenotype and genotype in Chinese women. Eur J Clin Pharmacol. 2000;56(9-10):689-92.

48 Selinski S, Blaszkewicz M, Getzmann S, Golka K. N-Acetyltransferase 2: ultra-slow acetylators enter the stage. Arch Toxicol. 2015; 89(12):2445-7.

49 Timbrell JA, Harland SJ, Facchini V. Effect of dose on acetylator phenotype distribution of hydralazine. Clin Pharmacol Ther. 1981; 29(3):337-43

50 Allen CE, Doll MA, Hein DW. N-Acetyltransferase 2 genotype-dependent $\mathrm{N}$-acetylation of hydralazine in human hepatocytes. Drug Metab Dispos. 2017;45(12):1276-81.

51 Arce C, Pérez-Plasencia C, González-Fierro A, de la Cruz-Hernández E, Revilla-Vázquez A, Chávez-Blanco A, et al. A proof-of-principle study of epigenetic therapy added to neoadjuvant doxorubicin cyclophosphamide for locally advanced breast cancer. PLoS One. 2006;1:e98.

52 Candelaria M, Gallardo-Rincón D, Arce C, Cetina L, Aguilar-Ponce JL, Arrieta O, et al. A phase II study of epigenetic therapy with hydralazine and magnesium valproate to overcome chemotherapy resistance in refractory solid tumors. Ann Oncol. 2007;18(9):152938.

53 Facchini V, Timbrell JA. Further evidence for an acetylator phenotype difference in the metabolism of hydralazine in man. Br J Clin Pharmacol. 1981;11(4):345-51.

54 Ludden TM, McNay JL Jr, Shepherd AM, Lin MS. Variability of plasma hydralazine concentrations in male hypertensive patients. Arthritis Rheum. 1981;24(8):987-93.

55 Rashid JR, Kofi-Tsepko T, Juma FD. Acetylation status using hydralazine in African hypertensives at Kenyatta National Hospital. East Afr Med J. 1992;69(7):406-8.
56 Shepherd AM, Ludden TM, McNay JL, Lin MS. Hydralazine kinetics after single and repeated oral doses. Clin Pharmacol Ther. 1980; 28(6):804-11.

57 Timbrell JA, Harland SJ. Identification and quantitation of hydrazine in the urine of patients treated with hydralazine. Clin Pharmacol Ther. 1979;26(1):81-8.

58 Timbrell JA, Harland SJ, Facchini V. Polymorphic acetylation of hydralazine. Clin Pharmacol Ther. 1980;28(3):350-5.

59 Zacest R, Koch-Weser J. Relation of hydralazine plasma concentration to dosage and hypotensive action. Clin Pharmacol Ther. 1972; 13(3):420-5.

60 Garcés-Eisele SJ, Cedillo-Carvallo B, ReyesNúñez V, Estrada-Marín L, Vázquez-Pérez R, Juárez-Calderón $\mathrm{M}$, et al. Genetic selection of volunteers and concomitant dose adjustment leads to comparable hydralazine/valproate exposure. J Clin Pharm Ther. 2014;39(4):368-75.

61 Graves DA, Muir KT, Richards W, Steiger BW, Chang I, Patel B. Hydralazine dose-response curve analysis. J Pharmacokinet Biopharm. 1990;18(4):279-91.

62 Jounela AJ, Pasanen M, Mattila MJ. Acetylator phenotype and the antihypertensive response to hydralazine. Acta Med Scand. 1975; 197(4):303-6.

63 Kalowski S, Hua AS, Whitworth JA, KincaidSmith P. Hydrallazine with beta-blocker and diuretic in the treatment of hypertension. A double-blind crossover study. Med J Aust. 1979;2(8):439-40.

64 Rowell NP, Clark K. The effects of oral hydralazine on blood pressure, cardiac output and peripheral resistance with respect to dose, age and acetylator status. Radiother Oncol. 1990;18(4):293-8.

65 Shepherd A, Lin MS, McNay J, Ludden T, Musgrave G. Determinants of response to intravenous hydralazine in hypertension. Clin Pharmacol Ther. 1981;30(6):773-81.

66 Shepherd AM, McNay JL, Ludden TM, Lin MS, Musgrave GE. Plasma concentration and acetylator phenotype determine response to oral hydralazine. Hypertension. 1981;3(5): 580-5.

67 Hunyor SN. Hydrallazine and beta-blockade in refractory hypertension with characterization of acetylator phenotype. Aust N Z J Med. 1975;5(6):530-6.

68 Spinasse LB, Santos AR, Suffys PN, Muxfeldt ES, Salles GF. Different phenotypes of the NAT2 gene influences hydralazine antihypertensive response in patients with resistant hypertension. Pharmacogenomics. 2014;15(2): $169-78$.
69 Sherry ST, Ward M, Sirotkin K. dbSNP-database for single nucleotide polymorphisms and other classes of minor genetic variation. Genome Res. 1999;9(8):677-9.

70 Batchelor JR, Welsh KI, Tinoco RM, Dollery CT, Hughes GR, Bernstein R, et al. Hydralazine-induced systemic lupus erythematosus: influence of HLA-DR and sex on susceptibility. Lancet. 1980;1(8178):1107-9.

71 Cameron HA, Ramsay LE. The lupus syndrome induced by hydralazine: a common complication with low dose treatment. $\mathrm{Br}$ Med J. 1984;289(6442):410-2.

72 Ihle BU, Whitworth JA, Dowling JP, KincaidSmith P. Hydralazine and lupus nephritis. Clin Nephrol. 1984;22(5):230-8.

73 Whelton PK, Carey RM, Aronow WS, Casey DE Jr, Collins KJ, Dennison Himmelfarb C, et al. 2017 ACC/AHA/AAPA/ABC/ACPM/ AGS/APhA/ASH/ASPC/NMA/PCNA Guideline for the prevention, detection, evaluation, and management of high blood pressure in adults: executive summary: a report of the American College of Cardiology/American Heart Association task force on clinical practice guidelines. J Am Coll Cardiol. 2018; 71(6):1269-324.

74 Morrow JD, Schroeder HA, Perry HM Jr. Studies on the control of hypertension by hyphex. II. Toxic reactions and side effects. Circulation. 1953;8(6):829-39.

75 Zschieschang P, Hiepe F, Gromnica-Ihle E, Roots I, Cascorbi I. Lack of association between arylamine $\mathrm{N}$-acetyltransferase 2 (NAT2) polymorphism and systemic lupus erythematosus. Pharmacogenetics. 2002; 12(7):559-63.

76 Baer AN, Woosley RL, Pincus T. Further evidence for the lack of association between acetylator phenotype and systemic lupus erythematosus. Arthritis Rheum. 1986;29(4):50814.

77 Shiokawa S, Yasuda M, Nobunaga M. Genotypes of polymorphic arylamine $\mathrm{N}$-acetyltransferase in systemic lupus erythematosus. Arthritis Rheum. 1992;35(11):1397-9.

78 Vedove CD, Del Giglio M, Schena D, Girolomoni G. Drug-induced lupus erythematosus. Arch Dermatol Res. 2009;301(1):99-105.

79 Lexicomp online. Lexi-drugs. Hudson, OH: Wolters Kluwer Clinical Drug Information Inc; 2020 